\title{
High concentration of ozone application by the DAF (Dissolved Air Flotation) system to treat livestock wastewater
}

\author{
B. H. Lee \& W. C. Song \\ Department of Civil and Environmental Engineering, \\ University of Ulsan, Korea
}

\begin{abstract}
It is known to be very difficult to treat livestock wastewater because it contains a lot of non-biodegradable organic material. Although many technologies have been employed to treat livestock wastewater such as ozone, AOP, Fenton, and membrane, including various microbiological technologies, they have not been very successful. High concentrations of ozone were applied to treat the livestock wastewater through the DAF (Dissolved Air Flotation) system, so that the DAF system employing ozone was named as the DOF (Dissolved Ozone Flotation) system. Ozone was used to substitute air in the DAF system. A high concentration of ozone provided a high potential of ozone oxidation and a high volume of micro-bubbles. Water quality parameters are removed by the two mechanisms of flotation and ozone oxidation. $\mathrm{COD}_{\mathrm{Mn}}$ was removed partly by flotation and partly by ozone oxidation. An average $81.1 \%$ of $\mathrm{COD}_{\mathrm{Mn}}$ was removed from $1,202 \mathrm{mg} / 1$ to $226 \mathrm{mg} / \mathrm{l}$. Suspended solids (SS) and total phosphorus (T-P) were removed mainly by flotation. An average $92 \%$ of SS were removed, from $1,504 \mathrm{mg} / 1$ to $49 \mathrm{mg} / \mathrm{l}$. $67.7 \%$ of $\mathrm{T}-\mathrm{N}$ removal was also achieved, from $112 \mathrm{mg} / 1$ to $32 \mathrm{mg} / 1.94 .6 \%$ of T-P was removed by flotation, from $97.81 \mathrm{mg} / \mathrm{l}$ down to $4.2 \mathrm{mg} / \mathrm{l}$. High ozone concentration with microbiological processes made it possible to meet the effluent standards of the livestock wastewater treatment.
\end{abstract}

Keywords: DAF, DOF, livestock wastewater, ozone, oxidation, flotation. 


\section{Introduction}

Even though livestock wastewater has contributed to pollution loading of the downstream, it has not been very successful in treating livestock wastewater, especially at the actual field treatment plants. Due to its non-biodegradability, physico-chemical processes were often employed along with biological processes in treating livestock wastewater, $[1,2]$. Various technologies have been employed to treat livestock wastewater including microbiological treatment such as SBR, and anaerobic digestion, [3-5]. Ozone has been used in treating various non-biodegradable wastewaters, $[6,7]$, such as fermentation, paper, and dye wastewater etc. Cho [8] suggested a treatment process of a livestock wastewater using screen, coagulation and sedimentation, ozone contact, and biological treatment. However, a typical process has not been established to treat livestock wastewater yet.

In this investigation a new technology using high concentration of ozone was applied in treating livestock wastewater. The new technology is the DOF (Dissolved Ozone Flotation) system with the PO2 (Pressurized Ozone Oxidation) processes. The DOF system is actually a DAF system which employs ozone instead of air. An ozone dissolving tank is used for oxidation of high concentration of organic matter in livestock wastewater, of which system is named as a Pressurized Ozone Oxidation (PO2 system) in this paper.

\section{Methods}

Research was performed using the DOF system installed at the treatment site of $\mathrm{P}$ city, Korea. Analysis was made for a five month period, from January 2006 to June 2006.

\subsection{System used in the research}

The schematic diagram of the DOF system with PO2 process is shown in Figure 1. The system was built with STS316 to resist in highly oxidative environment. The whole system was automated.

Influent enters the flotation system, and SS is removed here. After removing SS, effluent of the flotation system moves to the PO2 system where it is contacted with high concentration of ozone for about 30seconds. Some fraction of the treated water in the PO2 system is sent to the flotation system for supplying ozone micro-bubbles to remove SS (floc). The remaining fraction of water is sent to the releasing tank for further oxidation of organics in water. Unused ozone in the off-gas is removed at the ozone destruction system, and released out of the system.

Ozone is used instead of air in the DAF (Dissolved Air Flotation) system, and an ozone dissolving tank is used as an ozone contact system in the name of the PO2 system. 


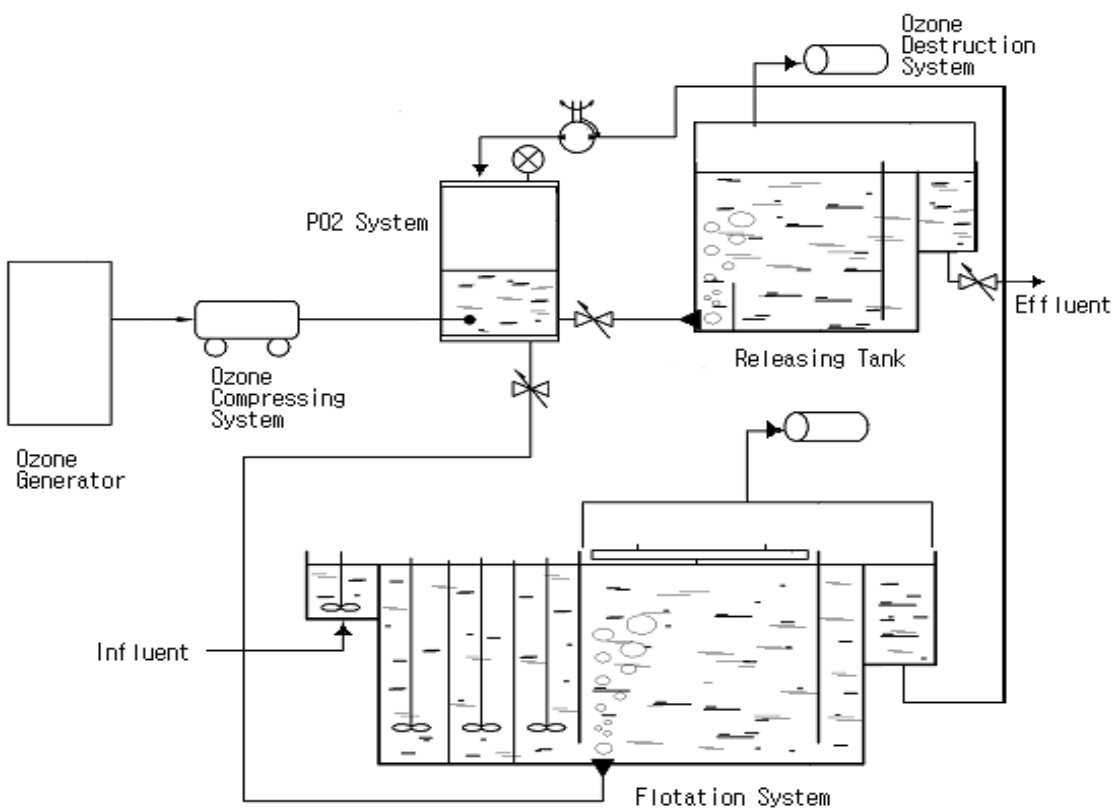

Figure 1: A diagram of the DAF system with ozone (the Dissolved Ozone Flotation, DOF system).

Table 1: Operating conditions of the DOF system.

\begin{tabular}{|c|c|c|c|c|c|}
\hline parameter & $\begin{array}{c}\text { flow rate } \\
\left(\mathrm{m}^{3} / \mathrm{hr}\right)\end{array}$ & $\begin{array}{c}\text { recycle } \\
\text { rate }(\%)\end{array}$ & $\begin{array}{c}\text { PO2 system } \\
\text { pressure } \\
\left(\mathrm{kg} / \mathrm{cm}^{2}\right)\end{array}$ & $\begin{array}{c}\text { ozone } \\
\text { dose } \\
(\mathrm{mg} / \mathrm{l})\end{array}$ & $\begin{array}{c}\text { Flotation time } \\
(\mathrm{min})\end{array}$ \\
\hline Average & 8.3 & 20 & 4.5 & $200-250$ & 20 \\
\hline
\end{tabular}

\subsection{Operating conditions of the system}

Operating conditions of the DOF system are presented in Table 1. Alum was used as a coagulant.

\section{Results and discussion}

\subsection{Background of the analysis}

The data of the paper was obtained from the actual livestock wastewater treatment plant in the B City of Korea. The wastewater of the plant was regularly collected from the several livestock farms in the regional area. Individual farms are not able to build their own treatment plants, and the government supports to build the public treatment plant. 
Water quality parameters in influent of the DOF system are presented in Table 2. The influent of the DOF system is the effluent of a biological treatment process. The whole process of the livestock wastewater plant consists of three unit processes, such as a biological contact batch system, the DOF system, and a continuous biological contact system.

Table 2: $\quad$ Water quality parameters in influent of the DOF system.

\begin{tabular}{|c|c|c|c|c|c|}
\hline Parameter & $\mathrm{pH}$ & $\begin{array}{c}\mathrm{COD}_{\mathrm{Mn}} \\
(\mathrm{mg} / \mathrm{l})\end{array}$ & $\begin{array}{c}\mathrm{SS} \\
(\mathrm{mg} / \mathrm{l})\end{array}$ & $\begin{array}{c}\mathrm{T}-\mathrm{N} \\
(\mathrm{mg} / \mathrm{l})\end{array}$ & $\begin{array}{c}\mathrm{T}-\mathrm{P} \\
(\mathrm{mg} / \mathrm{l})\end{array}$ \\
\hline average & 8.2 & $1,202.2$ & $1,503.9$ & 112.1 & 97.8 \\
\hline
\end{tabular}

The analysis of the paper is limited to the DOF system out of the whole process. Because it was very difficult to treat livestock wastewater to meet the effluent standards with other possible technologies, the DOF system was tried to employ two biological processes. Even though the whole data of the treatment plant including biological processes are not presented here because the analysis is limited to the DOF system, effluent standards could be obtained by the whole processes. The flotation process of the DOF system removed most of suspended solids, and the PO2 system lowered water quality parameters remarkably including non-biodegradable organic materials by ozone oxidation. Water quality parameters include $\mathrm{COD}_{\mathrm{Mn}}$, color, and UV-254 absorbance. However, the data analysis has been performed only for the $\mathrm{SS}, \mathrm{COD}_{\mathrm{Mn}}, \mathrm{T}-\mathrm{N}$, and T-P in this paper because those are the basic parameters that the environmental law regulates.

\subsection{Analysis of the data}

\subsubsection{Removal of COD $_{M n}$}

Influent concentration range of $\mathrm{COD}_{\mathrm{Mn}}$ of the DOF system was from about $780 \mathrm{mg} / 1$ to $2,200 \mathrm{mg} / 1$ with an average of $1,202.2 \mathrm{mg} / 1$. It was lowered down to about $90 \mathrm{mg} / 1$ to $400 \mathrm{mg} / 1$ with an average of $226.2 \mathrm{mg} / 1$ by the DOF system. The average removal rate of $\mathrm{COD}_{\mathrm{Mn}}$ was $81.1 \%$. $\mathrm{COD}_{\mathrm{Mn}}$ is removed along with suspended solids by flotation in the flotation tank, and by ozone oxidation in the PO2 system. Removal of $\mathrm{COD}_{\mathrm{Mn}}$ is presented in Figure 2.

Ozone is compressed into the PO2 system by the ozone pumping system up to about $4.5 \mathrm{~kg} / \mathrm{cm}^{2}$. An average ozone dose into the PO2 system was about $200-$ $250 \mathrm{mg} / 1$ depending upon the flow rate and quality of the influent. About $10 \%$ of ozone was produced by the volume basis using pure oxygen.

In order to look at the influence of ozone concentration in removing $\mathrm{COD}_{\mathrm{Mn}}$, ozone was applied in various concentrations from about $40 \mathrm{mg} / 1$ to $200 \mathrm{mg} / \mathrm{l}$ as shown in Figure 3. This experiment has been done for a short period of time at the beginning of plant operation.

As it may be seen in Figure 3, removal rates of $\mathrm{COD}_{\mathrm{Mn}}$ were over $88 \%$ for the whole range of ozone application. It may also be seen in Figure 3, the removal is 


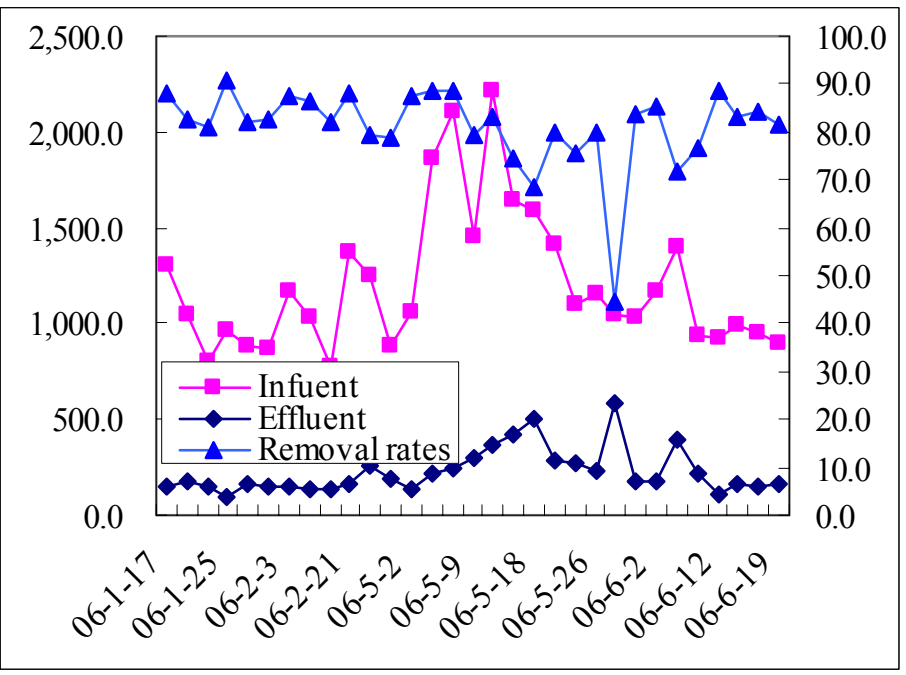

Figure 2: Removal rates, and influent and effluent concentrations of $\mathrm{COD}_{\mathrm{Mn}}$ of the DOF system (removed by flotation and oxidation).

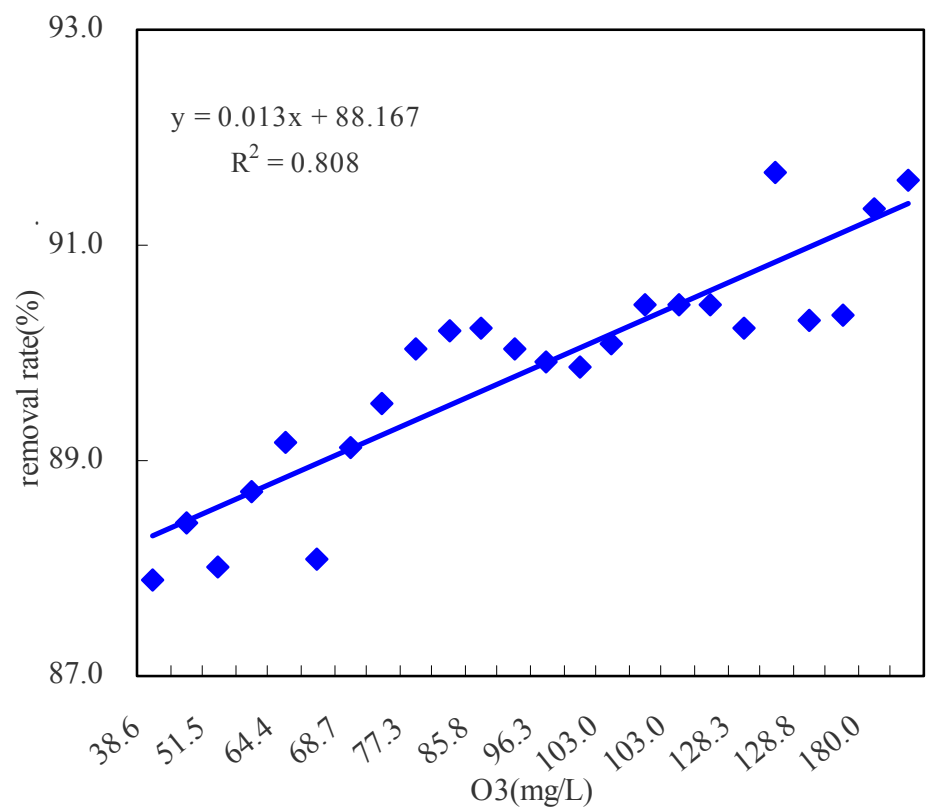

Figure 3: Effect of different concentrations of ozone in removal rates of CODMn. 
mostly accomplished by flotation with over $88 \%$ removal rate. There is a tendency for the $\mathrm{COD}_{\mathrm{Mn}}$ removal rate to increase, with increasing ozone concentration. There are two major reasons that high concentration of ozone can enhance the removal rates of water quality parameters. The first reason is that ozone enhances coagulation reaction efficiency of colloidal SS, Fe, and Mn by oxidizing hydrophilic material to hydrophobic one which is precipitated, and is removed after all. The second reason is that ozone has high water solubility, and as ozone concentration increases, the amount of micro-bubbles produced in the flotation system increases, which leads to enhance removal rates of SS.

\subsubsection{Suspended Solids (SS)}

Suspended solids are removed mostly by flotation. Even though the influent concentrations of SS were varied from $130 \mathrm{mg} / 1$ to $3,300 \mathrm{mg} / 1$ with an average of $1,504 \mathrm{mg} / 1$, the effluent SS concentrations were pretty much consistent as shown in Figure4. The SS concentrations in effluent of the DOF system were maintained from 4 to $188 \mathrm{mg} / \mathrm{l}$ with an average $49 \mathrm{mg} / \mathrm{l}$, during the period of the operation. An average removal rate of SS was about $92 \%$. It is very important to remove SS in the DOF system because the higher SS concentration is in effluent of the flotation system the higher ozone consumption rate is in the PO2 system. High concentration of ozone is supposed to be used in dissolved organic material which causes COD, color, and other water quality problems. If SS is not removed sufficiently, the remaining ozone is used to react with suspended solids, which is not the purpose of the ozone dose, and therefore ozone is wasted.

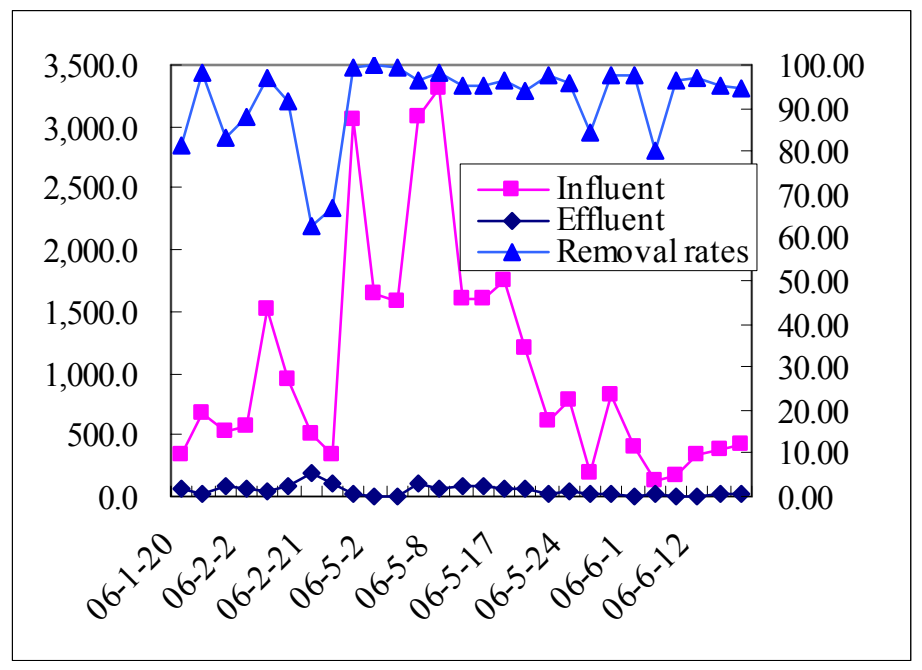

Figure 4: Removal rates, and influent and effluent concentrations of SS of the DOF system (removed by flotation).

Effect of ozone concentration in removal rate of SS has also been analyzed. As shown in Figure 5, removal rates of SS were over 90\% for the whole range of 
ozone application. The removal of SS is accomplished only by flotation. Even though the correlation of the regression line is relatively low, there is a clear tendency for the SS removal rate to increase with increasing ozone concentration. There are also the same two major reasons to enhance the removal rates by increasing ozone concentrations, such that ozone oxidation enhances coagulation reaction efficiency of colloidal SS, and dissolved Fe and Mn. Ozone also provides high volume of micro-bubbles to the flotation system, which leads to enhance removal rates of SS.

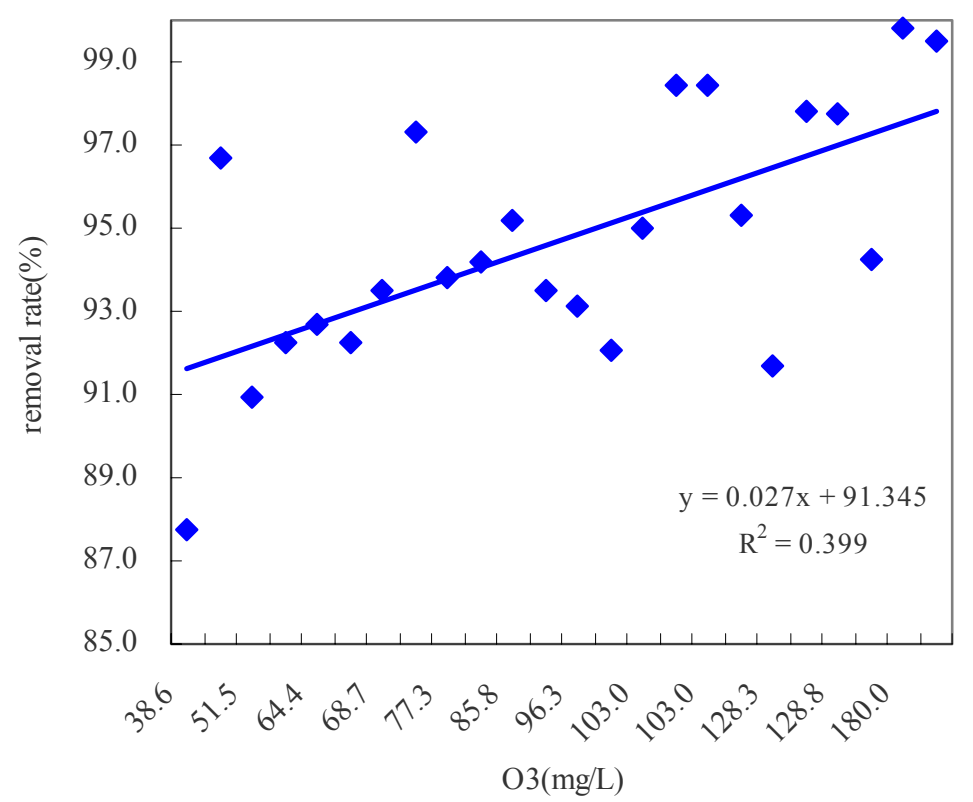

Figure 5: $\quad$ Effect of different concentrations of ozone in removal rates of SS.

\subsubsection{Total nitrogen (T-N)}

The DOF system was not that effective in removing $\mathrm{T}-\mathrm{N}$ as illustrated in Figure 6. Removal of suspended $\mathrm{T}-\mathrm{N}$ took place along with $\mathrm{SS}$ removal in this investigation, when sludge was scrapped out. Dissolved nitrogen should be removed by biological processes, so that actually a biological contact system was employed at the plant of the investigation. However, oxidation of nonbiodegradable organic matter by high concentration of ozone enhanced removal rate of dissolved organic nitrogen at the following biological process. Nitrogen concentration in influent of the DOF system was $112.1 \mathrm{mg} / 1$, which was lowered down to $36.1 \mathrm{mg} / \mathrm{l}$. An average removal rate of T-N was about $67.7 \%$.

It is somewhat difficult to remove T-P (Total Phosphorus) by the biological contact process because the biological contact system does not produce much sludge. However, T-P was removed effectively through a coagulation and 
flocculation reaction followed by the flotation in the DOF system. $94.6 \%$ of T-P was removed during the operation period, from about $98.8 \mathrm{mg} / \mathrm{l}$ to about $4.2 \mathrm{mg} / \mathrm{l}$ as shown in Figure 7. T-P was removed along with the flocculated sludge.

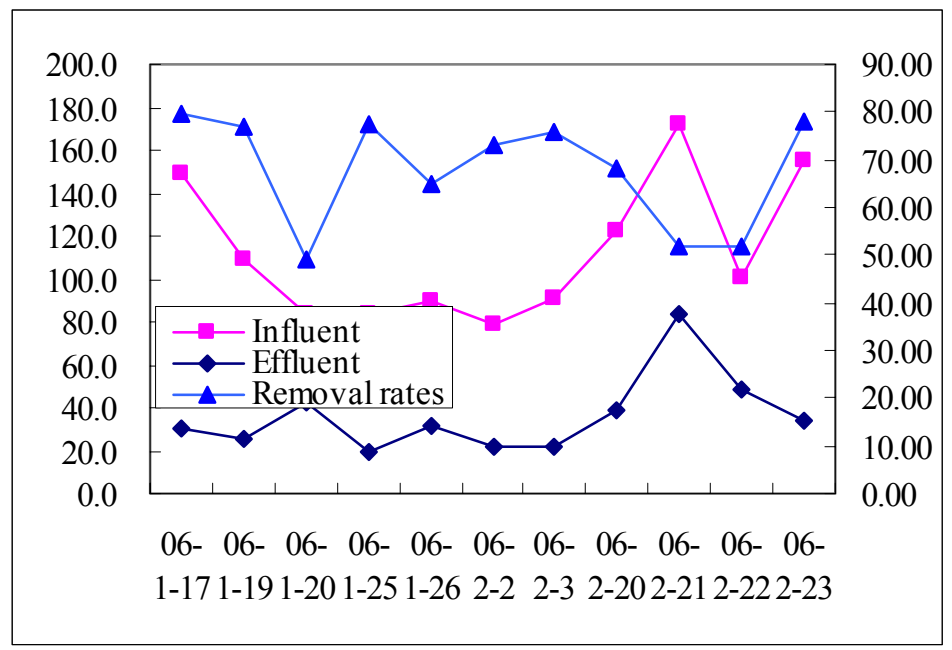

Figure 6: Removal rates, and influent and effluent concentrations of T-N of the DOF system (removed by flotation).

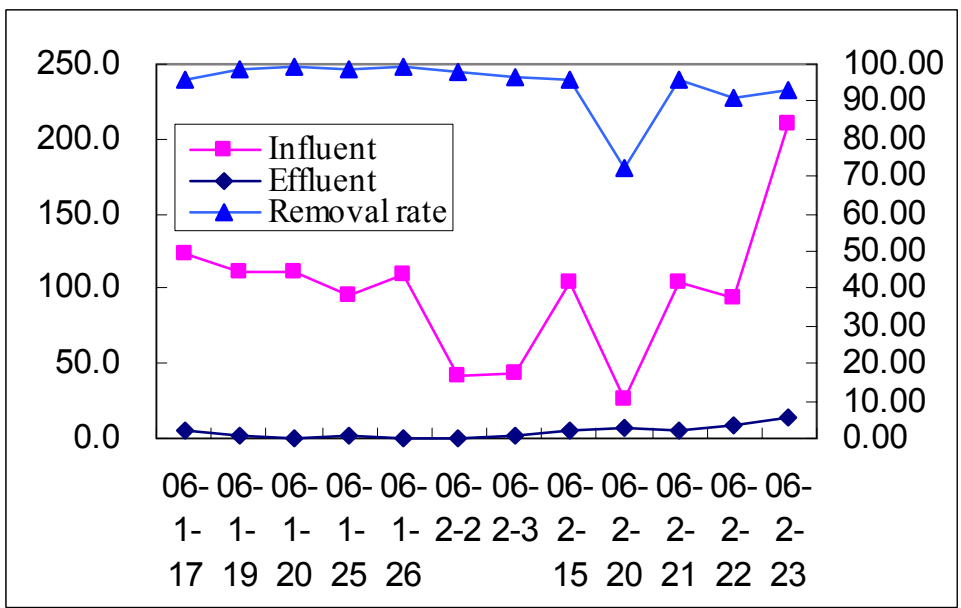

Figure 7: Removal rates, and influent and effluent concentrations of T-P of the DOF system (removed by flotation). 


\section{Conclusion}

Livestock wastewater often contributes to loading of pollution at the down stream. Even if its production is not great, it normally contains high concentration of non-biodegradable organic material.

High concentration of ozone was applied to the livestock wastewater using the DAF system, of which was named as the DOF system. The contact time of high concentration of ozone was about 30seconds in the PO2 system of the DOF process. Suspended sludge is removed in the flotation system as sludge.

$81.1 \%$ of an average CODMn was removed, from $1,202 \mathrm{mg} / \mathrm{l}$ to $226 \mathrm{mg} / \mathrm{l}$ by flotation and ozone oxidation. An average of $92 \%$ of suspended solids (SS) were removed, from $1,504 \mathrm{mg} / \mathrm{l}$ to $49 \mathrm{mg} / \mathrm{l}$ by flotation. Even if T-N removal was not much effective by high concentration of ozone, T-N was removed along with sludge. $67.7 \%$ of T-N removal was achieved, from $112 \mathrm{mg} / 1$ to $32 \mathrm{mg} / 1.94 .6 \%$ of T-P (total phosphorus) was removed by flotation, from $97.81 \mathrm{mg} / \mathrm{l}$ down to $4.2 \mathrm{mg} / \mathrm{l}$. High concentration of ozone provided high potential of oxidation, and high volume of micro-bubble.

\section{References}

[1] Chang, J.K. \& Hwang, K.D., Removal of Residual Organic Matter in the Biologically Treated Swine Wastewater. Pro. of the KSWWA and KWEA Annual Fall Conference: KWCO. D-11, pp. 305-308, 2000.

[2] Park, J.H., Chang, S.W. \& Cho, I.H., Optimal Condition of Operation Parameter for Livestock Wastewater Treatment Using Photo-Fenton Process. Jour. of KSWQ, 21(3), pp. 284-288, 2005.

[3] Jun, B.H., Poo, K.M., Choi, E.H., Lee, H.I. \& Kim, C.W. HighPerformance SBR Operation by Optimized Feeding Method of External Carbon Source for Piggery Wastewater Treatment. Jour. of KSEE 24(11), pp. 1957-1964, 2002.

[4] Ahn, Y.H., Bae, J.Y., Park, S.M. \& Min, K.S., High Performance Anaerobic Treatment of Piggery Waste-Anaerobic Digestion Elutriated Phased Treatment Process. Jour. of KSCE, 24(2B), pp. 155-161, 2004.

[5] Lee, S.K., Park, S.H., Cho, C.H. \& Lim, B.R., A Study on the Swine Wastewater Treatment Using Sequencing Batch Reactor(I). Jour. of KSWES, 15(1), pp. 49-56, 1998.

[6] Coca, M., Pena, M. \& Gonzalez, G., Variables affecting efficiency of molasses fermentation wastewater ozonation. Chemosphere 60, pp $1408-$ $1415,2005$.

[7] Amat, A.M., Arques, A., Miranda, M.A.\& Lopez F. Use of ozone and/or UV in the treatment of effluents from board paper industry. Chemosphere 60, pp. 1111-1117, 2005.

[8] Cho, W.H. A study on the Livestock Wastewater Treatment by the Microscreening, Chemical Coagulation, and Ozonation. Jour. of Environmental Research, Korea, 1(1), pp. 137-143, 2001. 